\title{
Lithology and porosity heterogeneity prediction using multiple seismic attributes on 3-d surveys: an example from Edim oil field, Niger delta
}

\author{
P. A. Alao ${ }^{1 *}$, C. E Nwoke ${ }^{2}$, S. O. Olabode ${ }^{3}$, A. Ata ${ }^{4}$ \\ ${ }^{1}$ Department of Geology, Institute of Earth and Environmental Sciences, University of Freiburg, \\ Albertstraße 23b, 79104 Freiburg, Germany \\ 2 School of Earth, Atmospheric and Environmental Sciences, The University of Manchester, Oxford Road, \\ Manchester, Greater Manchester M13 9PL, UK \\ ${ }^{3}$ Department of Applied Geology, Federal University of Technology Akure, P.M.B 704 Akure, Ondo State, Nigeria \\ ${ }^{4}$ Department of Geology, University of Malaya, Kuala Lumpur, Malaysia \\ *Corresponding author E-mail: alaoptr@gmail.com
}

\begin{abstract}
This research work presents the result of integrating three-dimensional (3-D) seismic attributes and log data to determine rock property (porosity and lithology) distribution of cretaceous-aged sandstones from Edim field, in the Niger Delta. The rocks are composed of thick sandstones which are resolvable in the seismic sections and possessing good petrophysical attributes for consideration as economic reservoirs. The method used was to invert the seismic data to elastic rock properties and then interpret these rock properties in terms of reservoir properties. Three seismic attributes which are considered important in exploration for fault-related reservoirs was employed. This study explores the stratigraphy and structure of the reservoir using 3-D seismic data and multiple seismic attributes to predict porosity and the net-to-gross. By predicting porosity and lithology using seismic attributes, lateral distributions of porosity that can be used to guide development and exploration drilling for optimal hydrocarbon recovery were obtained. The sites of highest porosity and net-togross were found to be along and within the fault zones. This study has indicated a close relationship between faulting and reservoir development by examining relationships using 3-D seismic data. Methods and results presented in this study can be used to explore and develop fault-related reservoirs in the Niger Delta and other similar geologic settings.
\end{abstract}

Keywords: Porosity, lithology, net-to-gross, predict, seismic attribute, Niger delta.

\section{Introduction}

In characterizing hydrocarbon reservoirs, estimating reserves, and developing models for how to best extract the hydrocarbons, it is useful to know the lithology (for example, relative amounts of shale and sand) and associated porosity of the rocks in the target interval. Rock properties can be measured directly from rock samples obtained from wells but such samples are generally very limited in availability due to the expense of drilling those wells. These properties can also be inferred from seismic data. Because of the complicated nature of the theoretical relationships between the seismic data (reflectivity) and the important rock properties (lithology, porosity, and fluid content), these two quantities are often related in practice through empirical relationships derived at wells, where both seismic and well measurements coexist. These empirical relationships are then applied to the entire volume of seismic data (or attributes derived from them) in order to make predictions about rock properties away from the wells. The problem is that empirical models require a statistically significant sampling of data and yet the wells provide very limited and generally biased samples of the reservoir properties. In regions where a large number of wells have been drilled, pattern-based recognition methods and simple empirical relationships can be used successfully to infer rock properties from seismic data. However, in regions of limited well control as in this research work, it is difficult to make accurate lithology prediction using empirical relationships derived from just a few wells.

\section{Methodology}

The estimation of rock properties using seismic data and derived attributes has always been a very important but challenging task. There are several methods for achieving this goal. All of them are based on strong and constraining a prior information. In quantitative reservoir characterization, we try to extract absolute information about reservoir rocks from the seismic data. The method adopted in this research work is to invert the seismic data to elastic rock properties and then interpret these rock properties in terms of reservoir properties. Genetic inversion was applied on the post stack seismic data to generate the acoustic impedance. In the case of genetic inversion, the required inputs are limited to the seismic amplitude, and the acoustic impedance well logs used as training data unlike other inversion methods. Indeed no single unique wavelet, neither initial property modeling are needed as inputs prior to run the inversion. Seismic at- 
tributes were also computed from the post stack data sets. Some of the attributes, called "Physical Attributes", such as envelope and phase are computed from the complex trace and correspond to various measurements of the propagating wave-front. The envelope attribute is of importance detecting bright spots caused by gas accumulations, detecting major lithological changes that are caused by strong energy reflections and sequence boundaries. Other attributes were computed from reflection configurations and continuity and are called "Geometric Attributes". These are used in structural and stratigraphic interpretation. Cross plots (figure 1) were generated between log derived acoustic impedance and porosity for individual well and also for the wells together in the reservoir zone. The cross plot for porosity versus acoustic impedance was used to define a function to convert acoustic impedance volume into porosity volume. Same was also used for the volume of shale in the case of lithology. The seismic attributes were then validated with log derived acoustic impedance and porosity.

The motivation for using seismic reflection data to characterize the spatial distribution of porosity and lithology comes from the ability to provide useful relationships between the seismic reflection data and physical properties.

\section{Discussion and results}

Attempts have been made to predict the distribution of physical properties as porosity and lithology within the reservoir layers by extracting seismic attributes from 3D-seismic data.

Envelope attribute slice at $2440 \mathrm{~ms}$ (figure 2) show the fluid distribution as bright spots indicated by high amplitudes. The fluid and lithological variation were observed to be fault controlled. Half energy attribute was extracted over the reservoir intervals which expressed the asymmetric changes in porosity within reservoirs. Sum of positive amplitude was used to determine areas with high net sand ratio. It is the arithmetic mean of the positive amplitudes, multiplied by the number of samples in the window; this operation provides a measure of brightness multiplied by the formation thickness (in time) and may be regarded as a measure of brightness volume. Petro physical results (table 1) of reservoir A in Edim 04 gives the porosity to be $19.12 \%$ but from the seismic attribute map (figure 3), porosity of $19.0 \%$ was predicted which gives a degree of accuracy in the prediction at well positions; though the level of accuracy is expected to reduce away from wells but this permits an understanding of the general variations in the distribution of the petro physical attributes useful for well planning and field development. On the second closure (C2) along the easterly bounding fault, the porosity is slightly higher than in the present.

Closure where existing wells are drilled. At the western end of the map (figure 3), very high porosity was observed. This suggests nearness to a depocenter as the porosity generally decreases from the northwest to the southeast. Porosity distributions along the faults are fairly even, suggesting that the distribution of petrophysical attributes is controlled by the faults. From petrophysical analysis of reservoir D, the porosity is $24.08 \%$. Seismic attribute map (figure 5) predicts the porosity at this well location to be $24.10 \%$ which also shows high level of reliability for this reservoir. The reservoir zones where wells have penetrated evidently have distinct porosity values from the surrounding porosity values which are very low at the eastern end of the closure. Similarly, as in reservoir A, the porosity is higher at the northwestern end of the map but generally reduces north-south depicting there is a depocenter at the northern end which could have accounted for the reduction in porosity southward. For reservoir G, irregular pattern was observed from the half energy attribute map (figure 7) but the porosity generally decreases towards the northeastern section of the map suggesting a depocenter is located toward the southwestern end.
From the sum of amplitude attribute map generated for reservoir A, the closure against the minor easterly fault has a higher net sand ratio than the present closure drilled which depicts that the sand in the second closure are relatively thicker and cleaner than the first closure. From this map (figure 4), it is apparent that sand development in this field is dominantly controlled by the faults which accounts for thick sands in the closures against faults. This is not alien to the Niger Delta as demonstrated in works by several researchers as Doust and Omatsola (1989), Evamy et al (1978). The higher sand thickness in the second closure would likely be as a result of the direction of the depocenter earlier mentioned. Attribute map for reservoir D divulges the closure where the present wells drilled to have a good net sand thickness. The direction of the distribution of the sand further confirms the northwestern location of a depocenter. The relation between the sand distribution and structures cannot be ascertained for this reservoir except through further studies. Sum of positive amplitude map (figure 6) for reservoir $\mathrm{G}$ reveals an isolated geologic feature at the north central end of the map which could be a stratigraphic trap. The sand distribution is evidently controlled by the structure with all the closure having medium sand thickness.

\section{Conclusion}

The results of the reservoir characterization provided a better understanding of the complexity in porosity variation, sand distribution, and their fluid content throughout the field. All the wells presently drilled in this field fall in areas where sum of positive amplitude are extremely high, also, on half energy map indicate high frequency on these locations. Seismic attribute maps have been proven in this research to provide good information between good and poor reservoir properties.

\section{References}

[1] Bhardwaj B.M., Juyal B.M., Arun K. G, Datta K., Ashish K and Gupta S.K. (2004): Quantative Analysis of Reservoir Characterisation through Seismic Attributes in Bassein Formation, Bombay Offshore Basin. Proceedings of 5th Conference \& Exposition on Petroleum Geophysics, Hyderabad-2004, India. p662-667.

[2] Brown, A.R. (1996): Seismic attribute and their classification. The Leading Edge, October. Chen Q. And Sidney S. (1997): Seismic attribute technology for reservoir forcasting and monitoring, The Leading Edge Vol. 16, p445-456.

[3] Doust, H. and Omatsola E. (1989): Niger Delta: American Association of Petroleum Geologists Memoir 48, p. 201-238.

[4] Doust, H. and Omatsola E. (1990): Niger Delta, in J.D. Edwards and P.A. Santogrossi, eds., Divergent/passive margin basins: American Association of Petroleum Geologists Memoir 48, p. 239-248.

[5] Evamy, B.D, Molloy, F.A, \& Rowlands, P.H. (1978): Hydrocarbon habitat of tertiary Niger Delta. AAPG Bull 62:1-39.

[6] Pennington, W.D. (1997): Seismic Petrophysics: An applied science for reservoir geophysics. The Leading Edge, March, pp 242-244.

[7] Peter, G.L. (2009): Integrating geologic and Geophysical data through Advanced constrained Inversions, $\mathrm{PhD}$ Thesis university of British Columbia.

[8] Rijks, E.Y, Jauffred, J.S. (1991): Attribute extraction: An important application in any detailed 3D interpretation study, Geophysics The Leading Edge of Exploration. P687-684.

[9] Sheriff, R. E. (1991): Encyclopedic Dictionary of Exploration Geophysics: SEG.

[10]Tearpock, D.J., Biscke R.E. (1991): Applied subsurface geological mapping. John Willey and Sons New York, pp 122-187. 

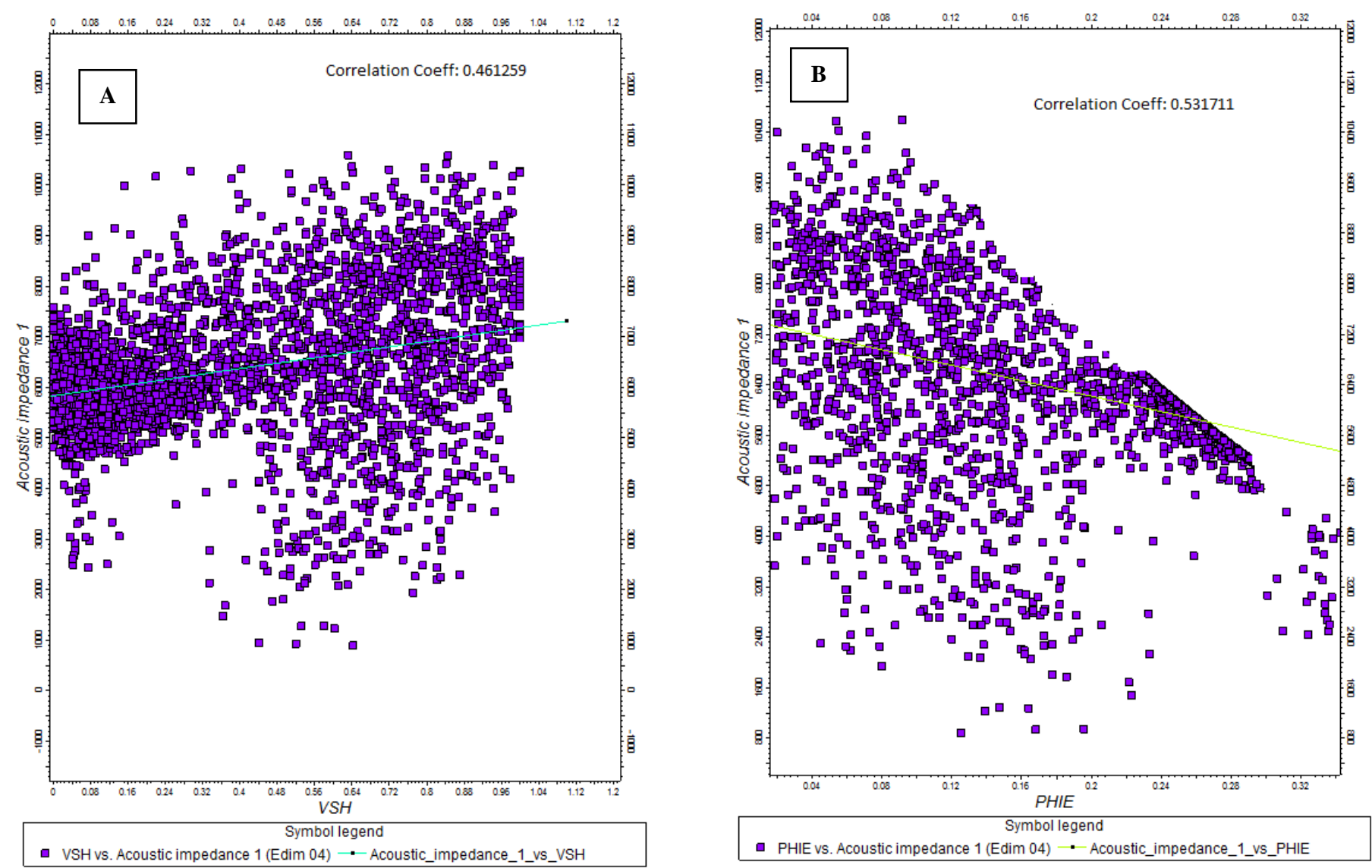

Fig. 1: Crossplot of Acoustic Impedance with volume of shale and effective porosity A: AI vs. Vsh B: AI vs. PHIE

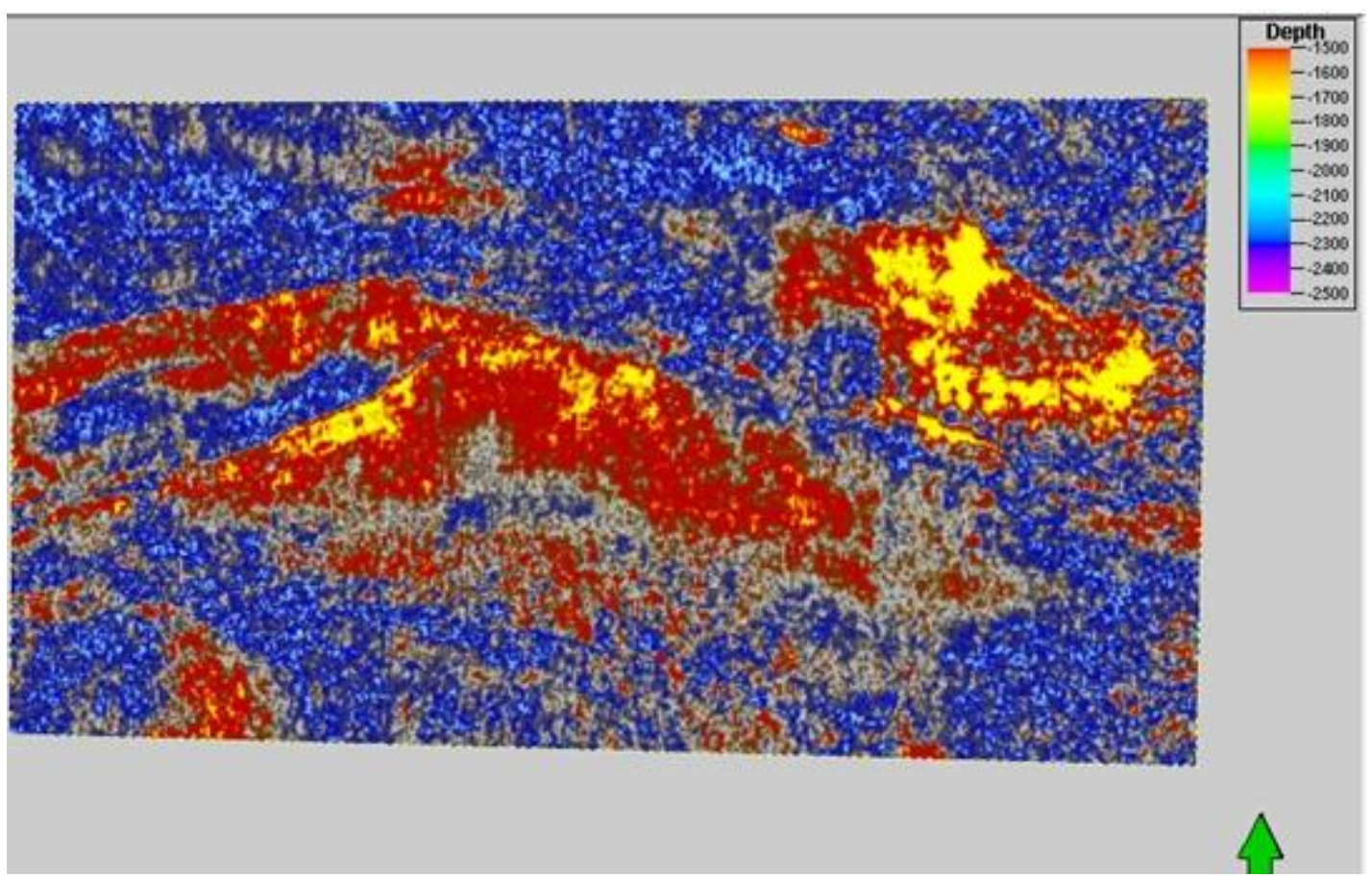

Fig. 2: Envelope time slice at $2440 \mathrm{msec}$ showing bright spots due to presence of hydrocarbon 


\section{Half energy attribute for Reservoir A}

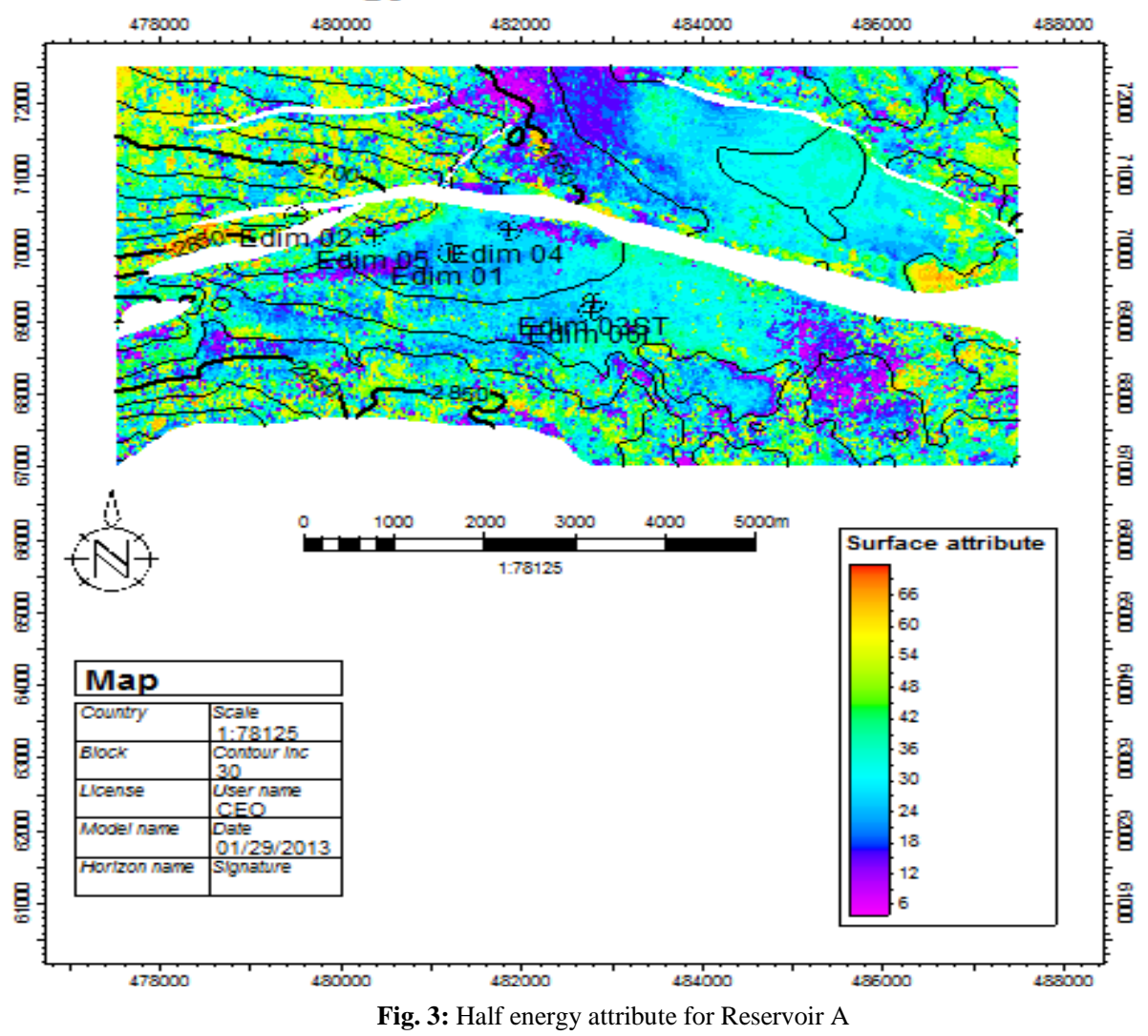

Sum of Positive Amplitudes for Reservoir A

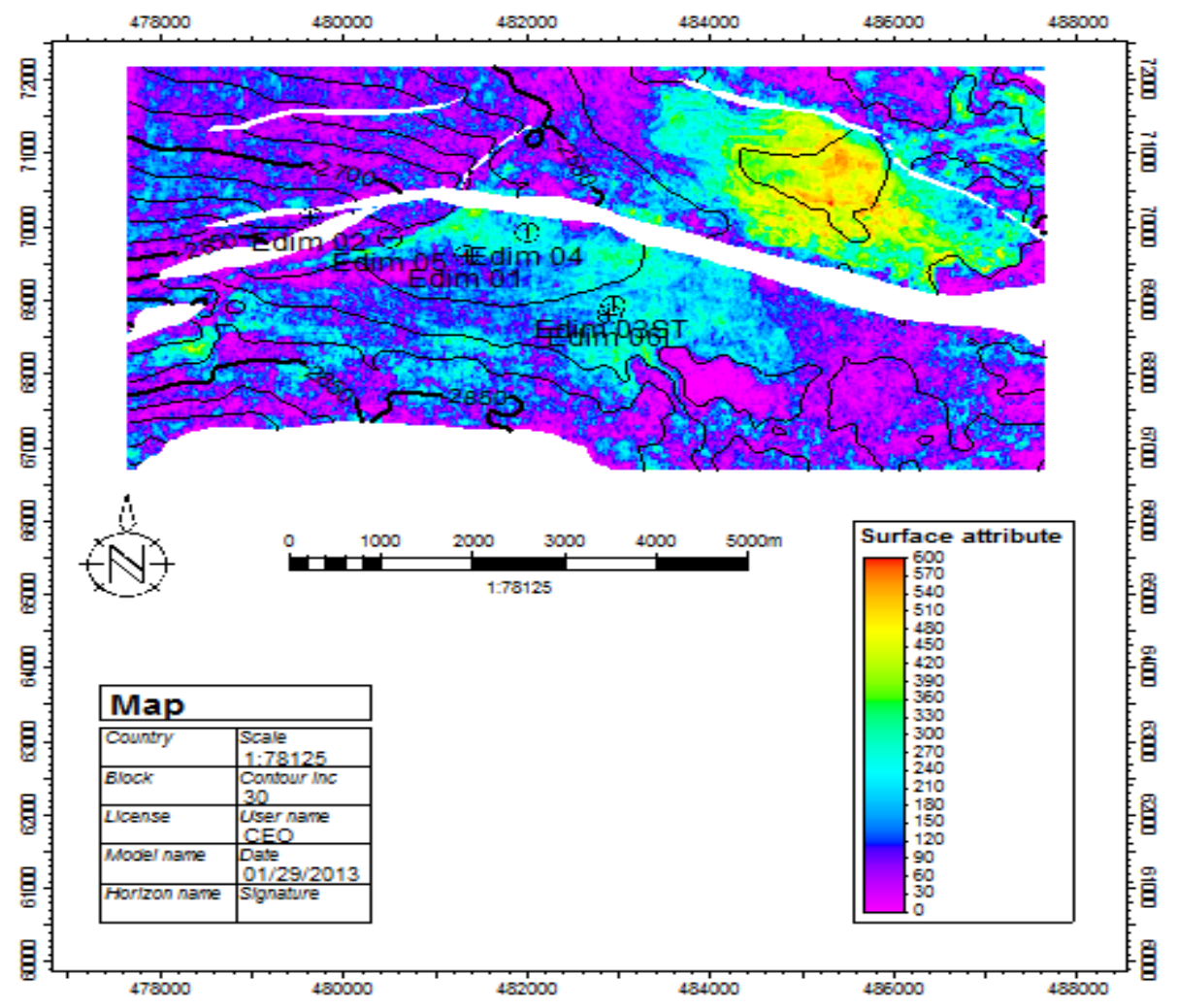

Fig. 4: Sum of positive amplitude for Reservoir A 


\section{Half energy attribute for Reservoir D}

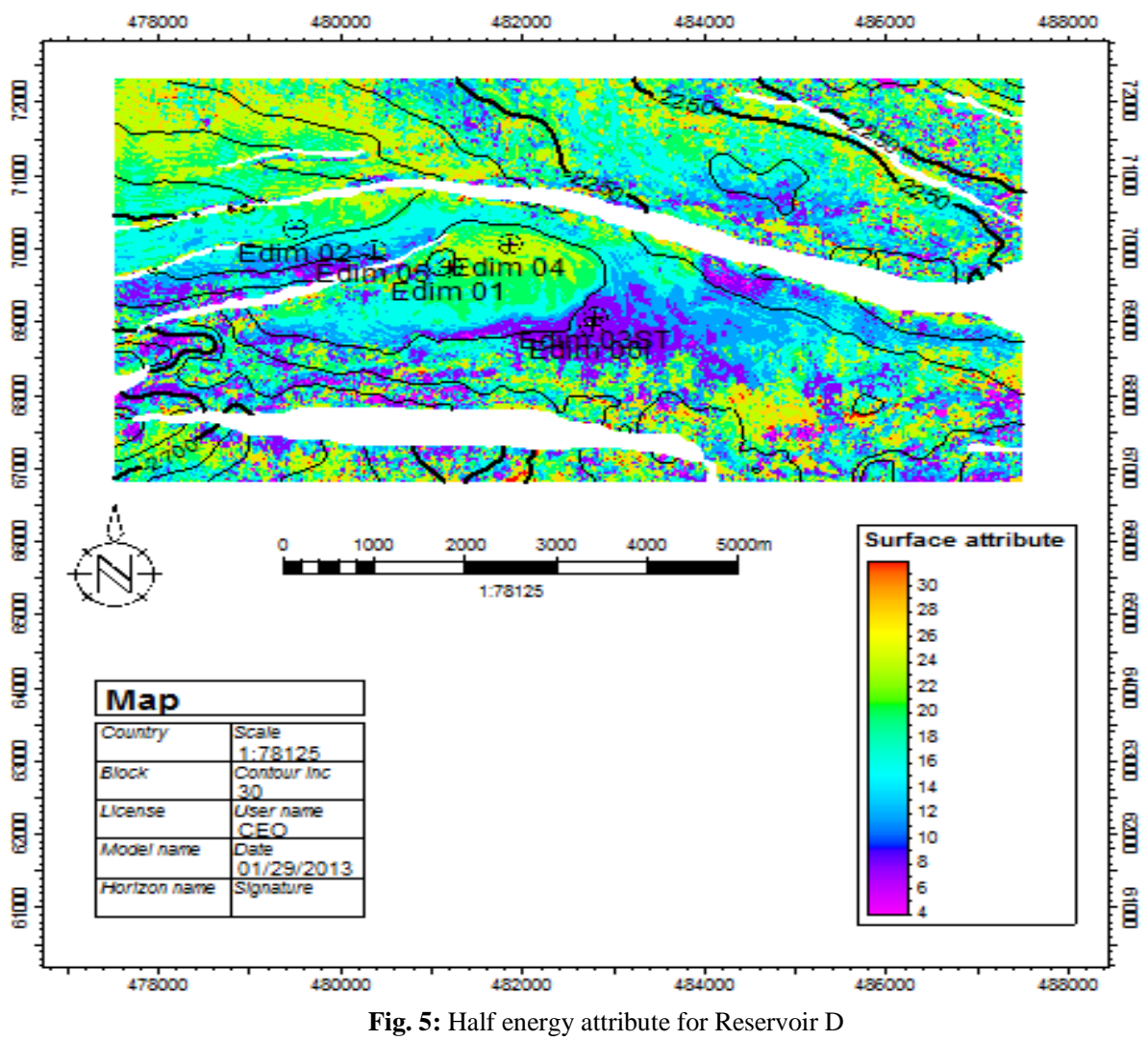

Sum of Positive Amplitudes for Reservoir D

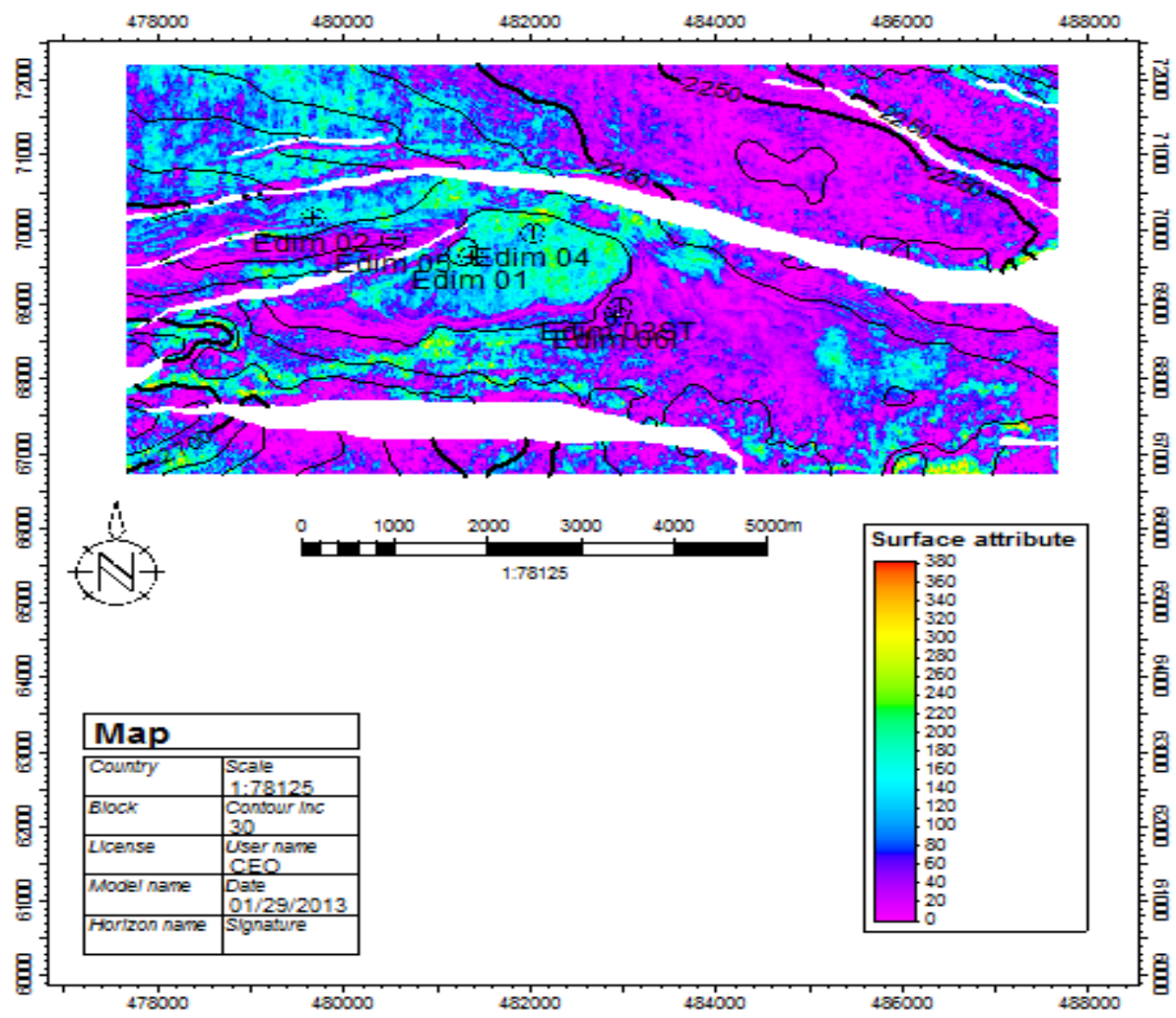

Fig. 6: Sum of positive amplitude for Reservoir D 
Half energy attribute for Reservoir G

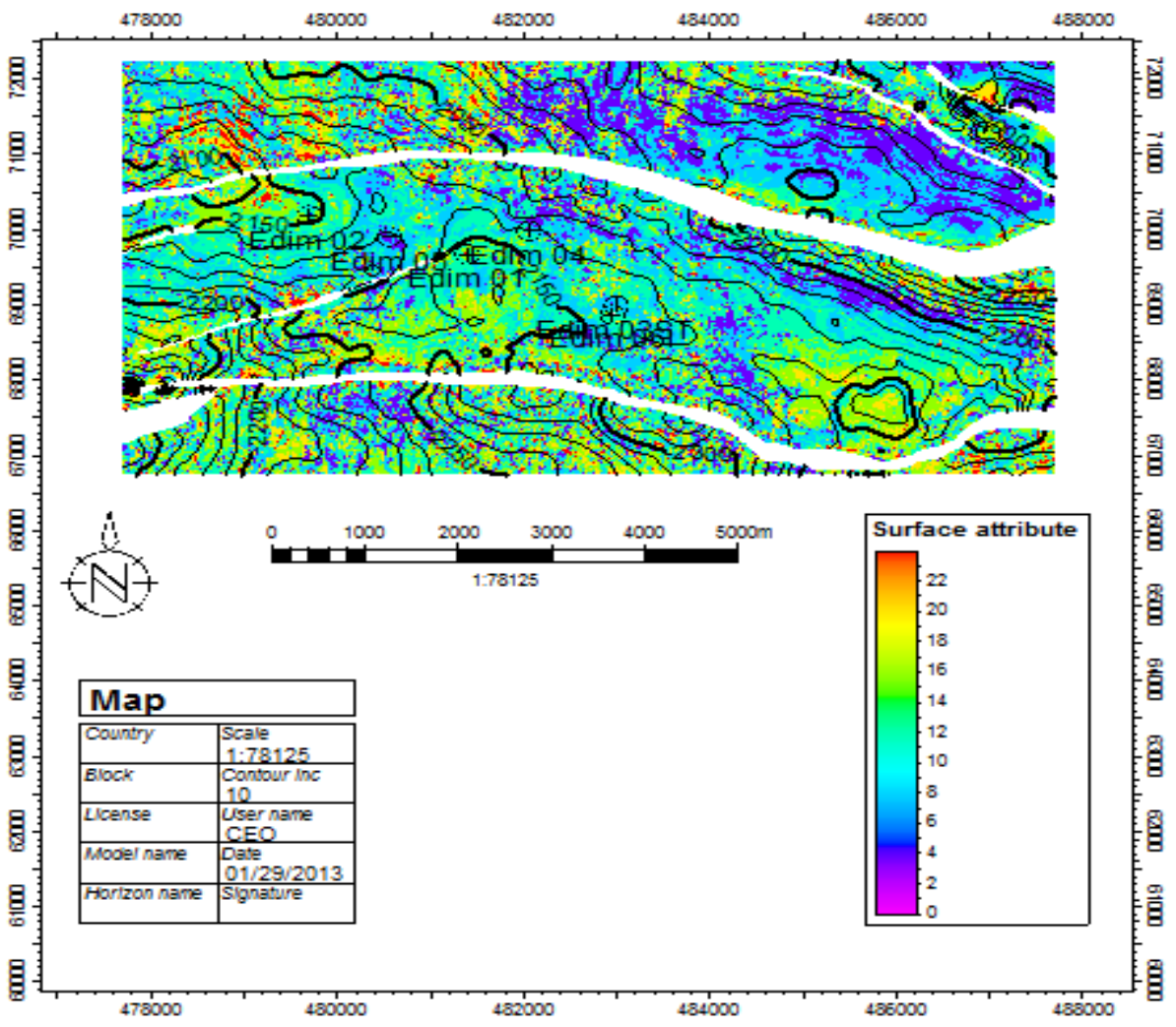

Fig. 7: Half energy attribute for Reservoir G

\section{Sum of Positive Amplitudes for Reservoir G}

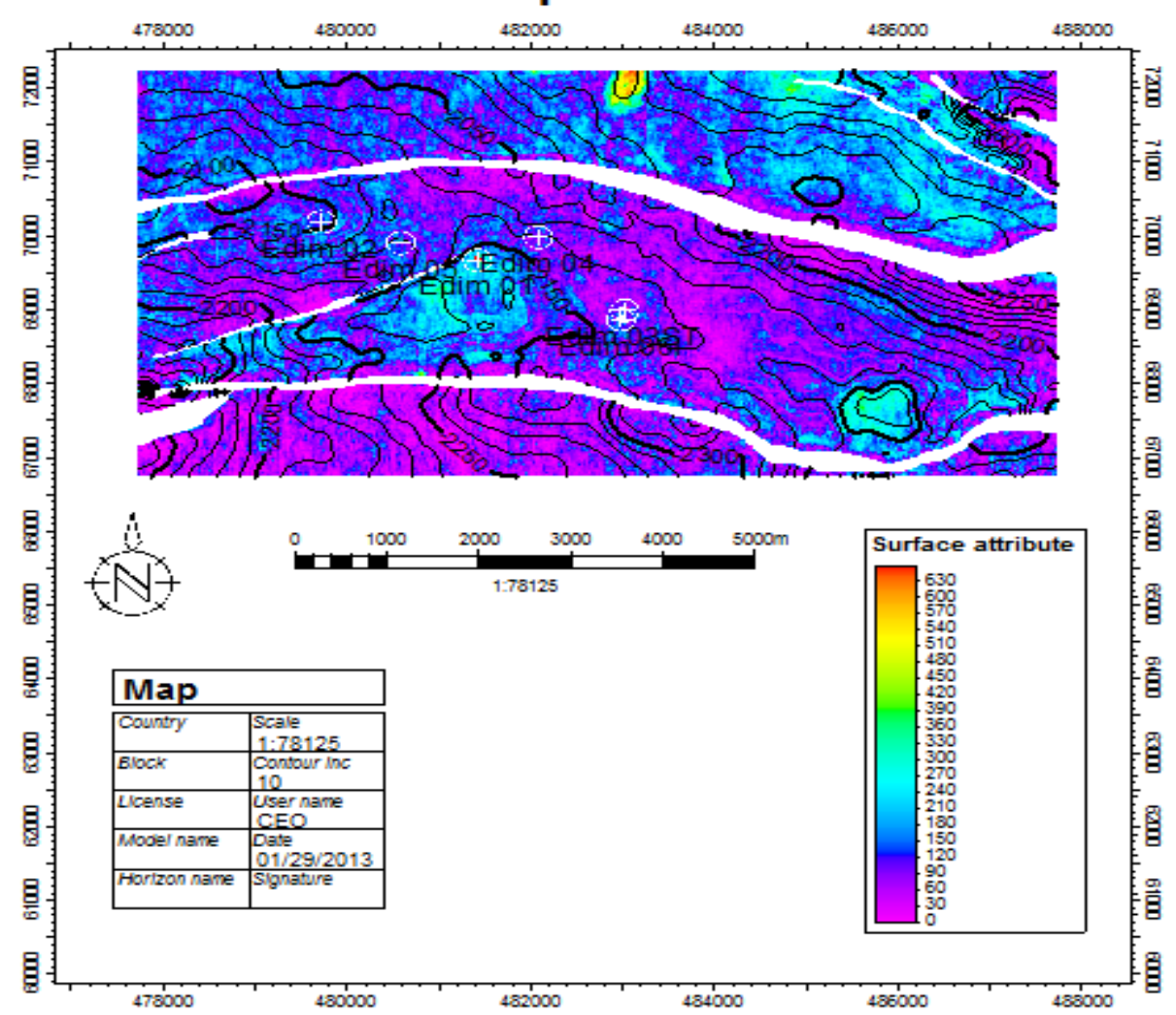

Fig. 8: Sum of positive amplitude for Reservoir G 